\title{
THE EFFECT OF CUSTOMER VALUE DIMENSIONS TO DESCRIBE CUSTOMER SATISFACTION AND BEHAVIORAL INTENTION OF SHARIA BANKS IN INDONESIA
}

\author{
Iwan Budiyono ${ }^{1}$, Eka Murtiasri ${ }^{2}$ \\ 1,2Politeknik Negeri Semarang, Semarang \\ $\triangle$ murtiasri.eka@gmail.com
}

\begin{abstract}
This study examines the relationship of customer value (CV) dimension added with the spirituality dimension to the satisfaction (KPN) and its impact on the Behavior Intention (BI) of the customers in Sharia Bank savings in Indonesia. Using a customer value approach that consists of: functional, social, emotional and spiritual. The sample consists of 41 people from the Sharia Bank savings of sharia bank population in Indonesia. Samples were collected through the spread of an online questionnaire. The method used is Multiple Linear Regression using SPSS 23 program. The result shows that there is positive influence of customer dimension to customer satisfaction, positive influence of customer value dimension toward behavioral intention and positive influence between customer satisfaction toward behavioral intention.
\end{abstract}

Keywords $\quad$ : intention; value; functional; social; emosional; spriritual.

\section{LATAR BELAKANG}

Populasi muslim di Indonesia merupakan populasi muslim terbesar di dunia. Hasil sensus penduduk dalam negeri pada tahun 2010 oleh BPS menunjukkan, bahwa jumlah muslim di Indonesia sebanyak 207.176.162 jiwa atau 87,18\% penduduk Indonesia yang beragama Islam (Badan Pusat Statistik). Jumlah ini membuktikan Indonesia menduduki peringkat pertama jumlah muslim didunia, disusul Pakistan, India dan Bangladesh (muslimpro.com). Dalam konteks pemasaran atau bisnis, besar konsumen muslim di Indonesia memiliki posisi dan potensi strategis untuk dikembangkan. Untuk menjawab peluang ini, berdirilah bank syariah yang memiliki fungsi intermediasi.

Meski memiliki peluang yang besar dalam bisnis syariah, namun fenomena bisnis syariah di Indonesia ternyata tidak sebanding. Dilansir dari infobank.news, Ketua Asosiasi Bank Syariah Indonesia (ASBISINDO), Moch Hadi Santoso yang mengatakan bahwa, peluang perbankan syariah untuk tumbuh masih sangat besar. Meski saat ini market share baru di kisaran 5 persen atau tepatnya 5,3\% (infobank.news). Selain itu, jumlah rekening tabungan BUS di Indonesia kian meningkat per bulannya dimulai dari bulan Januari - Juni. Disisi lain, pertumbuhan jumlah rekening tabungan BUS di Indonesia kian mengalami penurunan dalam kurun waktu 2017. Yaitu Januari - 
Februari tumbuh sebesar 1,54\%, Maret 1,42\%, April 1,41\%, Mei 1,03\% dan Juni $0,13 \%$.

Permasalahan tersebut akan diselesaikan melalui beberapa pendekatan yang berdasarkan pada penelitian terdahulu yaitu Customer Value (CV), Kepuasan Nasabah (KPN) dan Behavior Intention (BI). Penelitian ini merupakan penelitian replikasi untuk mengetahui bagaimana menyelesaikan permasalahan menurunnya minat masyarakat terhadap produk tabungan BUS di Indonesia. Perbedaan dari penelitian sebelumnya adalah pada kurun waktu serta pembentukan modelnya. Penelitian sebelumnya menjadi inspirasi dikarenakan, telah menambahkan dimensi spiritualitas pada customer value, sehingga pada penelitian ini langsung menerapkan dimensi customer value yang telah di bentuk tersebut. Selain itu penelitian ini menghubungkan antara pengorbanan serta manfaat yang diterima nasabah dalam satu item pertanyaan. Dengan demikian akan diketahui apakah pendekatan yang sama juga akan menjadi solusi pada kurun waktu yang berbeda serta dengan bentuk quest yang lebih komprehensif.

\section{TEORI DAN METODE}

\subsection{Kajian Teori}

Behavioral intentions adalah sikap atau perilaku yang akan ditunjukan pelanggan setelah melakukan menerima layanan.terdiri dari dimensi sebagai berikut:

Word of mouth, yaitu suatu suatu komunikasi yang dilakukan oleh pelanggan Amaris Hotel kepada orang lain yang dapat mempengaruhi orang lain (Bloemer, 2003).

Sensivitas harga, yaitu suatu kepekaan dari pelanggan terhadap perubahan harga yang terjadi (Bloemer, 2003).

Repeat Purchasing, yaitu keinginan pelanggan bersedia ulang untuk menginap di Amaris Hotel (Bloemer, 2003).

Menurut Kotler dan Armstrong (2000:9) Kepuasan konsumen adalah sejauh mana anggapan kinerja produk memenuhi harapan pembeli. Bila kinerja produk lebih rendah ketimbang harapan pelanggan, maka pembelinya merasa puas atau amat gembira.

Menurut Zeithaml dan Bitner (2000:75) definisi kepuasan adalah respon atau tanggapan konsumen mengenai pemenuhan kebutuhan. Kepuasan merupakan penilaian mengenai ciri atau keistimewaan produk atau jasa, atau produk itu sendiri, yang menyediakan tingkat kesenangan konsumen sesuai dnegan kebutuhan konsumen (customer).

Menurut Kotler (2006) yang terdapat pada penelitian Subagyo dan Robin (2012) Customer Value (nilai yang dirasakan) adalah suatu bentuk yang melandasi kualitas layanan yang dirasakan, sebagai bahan nilai, kualitas layanan yang dirasakan bisa jadi dikonsepkan sebagai hasil dan pertukaran atau penjualan pelanggan antara persepsi kualitas dan pengor-banan pelanggan dalam segi keuangan maupun non keuangan. Pengorbanan non keuangan seperti waktu, fisik atau usaha psikologis. 
Mengacu dari penelitian secara sebelumnya Afiff dan Rifelly (2009) dengan dimensi customer value sebagai berikut:

Customer Value berdasarkan Fungsional: aspek fungional produk, layanan dan harga. Customer Value berdasarkan Sosial: aspek sosial masyarakat.

Cuatomer Value berdasarkan Emosional: aspek emosional pribadi masyarakat.

Customer Value berdasarkan Spiritual: aspek keagamaan masyarakat.

\section{Tabel 1.1 Indikator-Indikator}

Behavioral Intantion

1. Saya menggunakan produk tabungan syariah yang lain.

2. Saya bersedia membayar biaya lebih untuk mendapatkan produk tabungan yang saya butuhkan di bank syariah.

3. Saya memberitahukan teman dan kerabat mengenai produk tabungan Bank Syariah.

Customer Satisfaction

1. Saya merasa puas dengan pelayanan Bank Syariah.

2. Saya merasa puas dengan keuntungan yang diberikan oleh Bank Syariah.

3. Saya merasa puas dengan fasilitas yang diberikan oleh Bank Syariah.

4. Saya merasa nyaman menabung di Bank Syariah.

5. Saya merasa percaya menabung di Bank Syariah.

Fungsonal Dimension

1. Bank Syariah memiliki jaringan yang luas sehingga saya menabung di Bank Syariah.

2. Bank Syariah memiliki reputasi yang baik sehingga saya menabung di Bank Syariah.

3. Karyawan Bank Syariah memiliki pengetahuan yang luas sehingga saya menabung di Bank Syariah.

4. Saya tetap menabung di Bank Syariah walaupun biaya administrasinya lebih tinggi dari Bank Konvensional.

5. Saya tetap menabung di Bank Syariah walaupun bagi hasil yang saya dapat lebih sedikit dari bunga yang diberikan Bank Konvensional.

\section{Social Dimension}

1. Saya menabung di Bank Syariah sehingga lebih dihargai masyarakat.

2. Saya menabung di Bank Syariah sehingga dipercaya oleh orang lain.

3. Saya menabung di Bank Syariah sehingga lebih di hormati orang lain.

4. Saya menabung di Bank Syariah meskipun berbeda dengan orang lain.

Emosional Dimension

1. Saya menabung di Bank Syariah sehingga saya merasa nyaman.

2. Saya menabung di Bank Syariah sehingga lebih percaya diri.

3. Saya menabung di Bank Syariah sehingga merasa senang.

4. Saya menabung di Bank Syariah sehingga merasa tenang.

Spiritual Dimension

1. Saya menabung di Bank Syariah sehingga saya dapat selamat dari azab Allah. 
2. Saya menabung di Bank Syariah sehingga saya lebih dekat dengan Allah.

3. Saya menabung di Bank Syariah sehingga saya telah melakukan perintah Allah.

4. Saya menabung di Bank Syariah walaupun tidak dapat menabung di Bank Konvensional.

\subsection{Metode Penelitian}

Penelitian ini mengambil sampel masyarakat yang menggunakan produk tabungan Bank Syariah yang dikumpulkan melalui kuisioner online. Responden berusia 19 tahun - 49 tahun dari berbagai jenis bank syariah yang berbeda. Metode yang digunakan adalah Regresi Linear Berganda yang dihitung dengan program SPSS 23. Model penelitian yang dibangun adalah sebagai berikut:

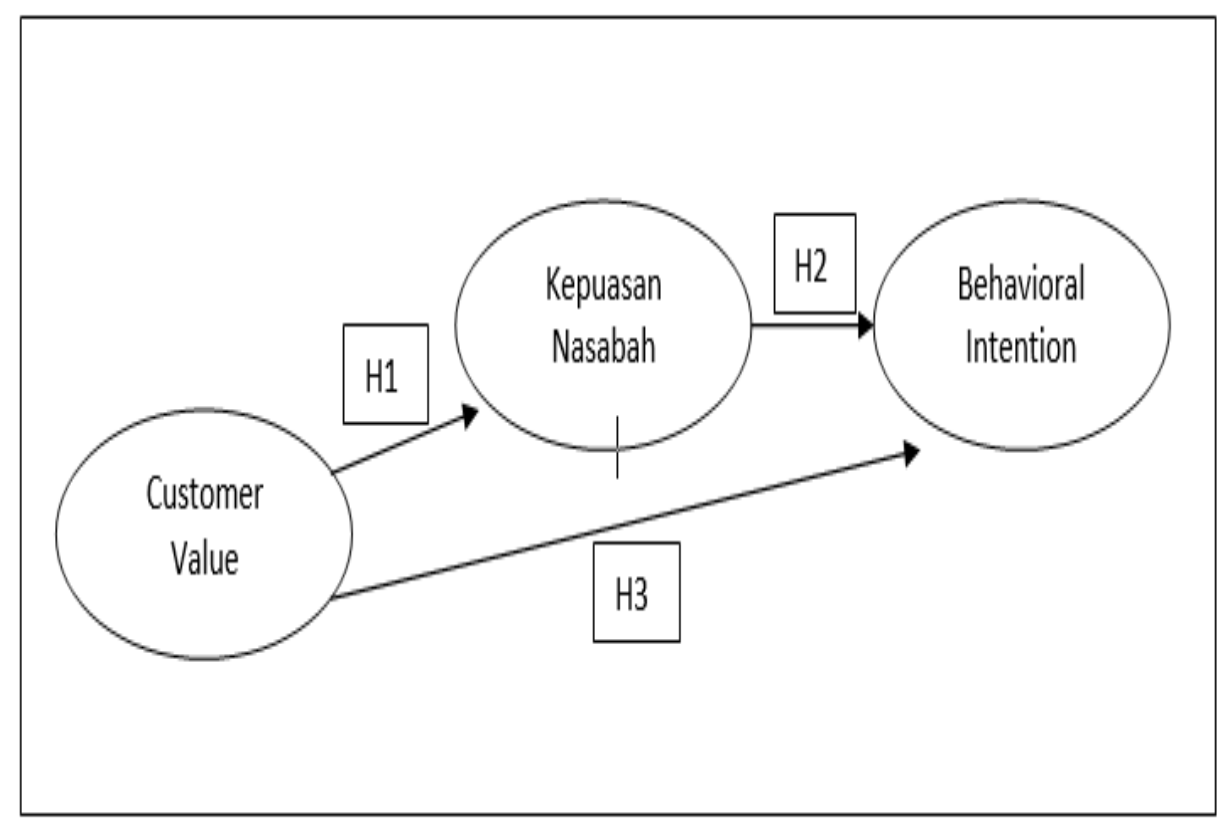

Sumber: Afiff dan Rifelly (2009); Wahyuningsih (2007); Park, Jaworki dan McInnis (1986); Tybout dan Crpenter (2001); Setyono dkk (2014); Hall and Edward (2002).

\section{HASIL DAN PEMBAHASAN}

\subsection{Validitas dan Reliabilitas}

Tabel 3.1

\begin{tabular}{|c|c|c|c|}
\hline & t-Tabel & t-value & Cronbach's Alpha \\
\hline \multicolumn{4}{|c|}{ Behavioral Intantion } \\
\hline BI1 & 0,308 & 0,753 & 0,753 \\
\hline $\mathrm{BI} 2$ & 0,308 & 0,603 & 0,752 \\
\hline
\end{tabular}




\begin{tabular}{cccc} 
BI3 & 0,308 & 0,747 & 0,747 \\
\hline Customer Satisfaction & & & \\
\hline CS1 & 0,308 & 0,833 & 0,751 \\
CS2 & 0,308 & 0,816 & 0,750 \\
CS3 & 0,308 & 0,797 & 0,751 \\
CS4 & 0,308 & 0,813 & 0,751 \\
CS5 & 0,308 & 0,827 & 0,749 \\
\hline Fungsonal Dimension & & & \\
\hline CVF1 & 0,308 & 0,683 & 0,753 \\
CVF2 & 0,308 & 0,795 & 0,751 \\
CVF3 & 0,308 & 0,714 & 0,752 \\
CVF4 & 0,308 & 0,706 & 0,751 \\
CVF5 & 0,308 & 0,749 & 0,751
\end{tabular}

\begin{tabular}{cccc}
\hline Social Dimension & & & \\
\hline CVSo1 & 0,308 & 0,428 & 0,756 \\
CVSo2 & 0,308 & 0,379 & 0,757 \\
CVSo3 & 0,308 & 0,311 & 0,758 \\
CVSo4 & 0,308 & 0,813 & 0,750 \\
\hline Emosional Dimension & & & \\
\hline CVE1 & 0,308 & 0,884 & 0,750 \\
CVE2 & 0,308 & 0,861 & 0,751 \\
CVE3 & 0,308 & 0,834 & 0,749 \\
CVE4 & 0,308 & 0,883 & 0,749 \\
\hline Spiritual Dimension & & & \\
\hline CVSp1 & 0,308 & 0,826 & 0,749 \\
CVSp2 & 0,308 & 0,864 & 0,749 \\
CVSp3 & 0,308 & 0,854 & 0,751 \\
CVSp4 & 0,308 & 0,719 & 0,748
\end{tabular}

\subsection{Uji Asumsi Klasik}

Normalitas: Distribusi data normal dlihat dari nilai signifikansinya yang telah lebih dari $\alpha$ 0,05 yaitu sebesar 0,35.Multikolerasi: Nilai VIF untuk KPN 2,009 > 2,00 maka tidak ada multikol. Dan VIF untuk CV sebesar 2,009 $>2,00$ menujukkan tidak ada multikolinearitas.Autokorelasi: Nilai DW menunjukkan 1,914 > dari nilai $\alpha$ 0,05 maka tidak terjadi autokorelasi. Heteroskedastisitas: Nilai Sig. per item menunjukkan > dari nilai $\alpha$ 0,05 maka tidak terjadi heteroskedastisitas, hal tersebut menunjukkan datanya homokedastisitas. 


\subsection{Uji Kelayakan Model}

Nilai F hitung > dari F tabel menunjukkan bahwa model memiliki hubungan simultan.

Uji t menguji hubungan masing-masing variabel terhadap Y. Hubungan X1 terhadap Yditunjukkan oleh nilai t CV 1,756 > t tabel. Hub X2 thd Y ditunjukkan oleh nilai $\mathrm{t}$ BI 4,228 > t tabel. Nilai Adjusted $R$ Square sebesar 0,644 menujukkan kemampuan variabel independen mendeskripsikan variabel dependen sebesar $64 \%$ dan sisanya dideskripsikan atau dipengaruhi oleh faktor lain yaitu $36 \%$.

\subsection{Uji Hipotesis}

\section{Pengaruh CV terhadap KPN}

Hasil menujukkan nilai t untuk CV terhadap KPN sebesar 6,2 sehingga meningkatkan minat nasabah menabung serta nilai sig. 0,000 menunjukkan pengaruh signifikan. Pengaruh CV terhadap KPN positif sigifikan.

\section{Pengaruh KPN terhadap BI}

Hasil menunjukkan nilai KPN terhadap BI sebesar 8,2 sehingga akan meningkatkan minat nasabah. Pengaruh Kepuasan Nasabah terhadap BI positif signifikan.

\section{Pengaruh CV terhadap BI}

Hasil menujukkan nilai CV terhadap BI sebesar 7,1 sehingga dapat meningkatkan Minat Nasabah Menabung. Serta nilai sig. 0.000 menujukkan pengaruh positif signifikan.

\section{PENUTUP}

Dari penelitian ini terdapat beberapa hasil sebagai berikut:

1. Pengaruh Customer Value terhadap Kepuasan Nasabah positif sigifikan.

2. Customer Value berpengaruh positif signifikan terhadap Behavioral Intention.

3. Pengaruh Kepuasan Nasabah terhadap BI positif signifikan.

Penelitian ini mengembangkan dimensi spiritual sebagai salah satu dimensi customer value. Sehingga dapat dijelaskan bahwa dimensi spiritual dapat menjadi salah satu dimensi customer value. Dan untuk meningkatkan minat nasabah dapat digunakan pendekatan Customer Value dan Kepuasan Nasabah. Dalam meningkatakan minat nasabah menabung sehingga dapat meningkatkan jumlah DPK pada Bank Syariah perlu dilakukan pendekatan Customer Value dan Kepuasan Nasabah.

Penelitian ini masih hanya melalui pendekatan Customer Value dan Kepuasan Nasabah untuk menjelaskan Minat Nasabah Menabung, diharapkan dapat dikembangkan dengan variabel-variabel lainnya pada penelitian berikutnya. 


\section{DAFTAR PUSTAKA}

Abdullah, Firdaus et al. 2011. Bank Service Quality (BSQ) Index An indicator of service performanceInternational Journal of Quality \& Reliability Management. Vol. 28 No. 5, 2011 pp. 542-555 q Emerald Group Publishing Limited 0265-671X DOI $10.1108 / 02656711111132571$.

Afiff dan Rifelly Dewi Astuti. 2009. The Addition of Spiritual Dimension on Customer Value to Investigate the Relationship of Customer Value, Customer Satisfaction and Behavior Intention on Islamic Banks Saving Products in Indonesia. ASEAN MARKETING JOURNAL June 2009 - Vol.I - No. 1.

Dewi, Kinorika. 2010. Pengaruh Company Image, Trust, dan Customer Satisfaction terhadap Customer Loyalty (Studi pada Konsumen Jasa Maskapai Penerbangan Domestik Bertarif Rendah. Efektif, Jurnal Bisnis dan Ekonomi Vol. I, No. 2, Desember 2010, 105 - 122

Ghozali, Imam. 2006. Aplikasi Analisis Multivariate Dengan Program SPSS. Semarang : Badan Penerbit Undip.

2011. Aplikasi Analisis Multivariate Dengan Program SPSS. Semarang: Badan Penerbit Undip.

Ifra Aldia Dolarosa. 2014. Pengaruh Karakteristik Syariah Marketing Terhadap Kepuasan Nasabah PT. Bank Mandiri Syariah Cabang Jember. Artikel Ilmiah Mahasiswa 2014.

Ishaq et al. 2014. Role of Corporate Image, Product Quality and Customer Value in Customer Loyalty: Intervening Effect of Customer Satisfaction. J. Basic. Appl. Sci. Res., 4(4)89-97, 2014. ISSN 2090-4304 Journal of Basic and Applied Scientific Research.

Jiwandono dan Suyanto. 2015. Pengaruh Customer Value Terhadap Loyalitas Pelanggan Operator Selular Telkomsel, Indosat, dan XL di Kota Bandung Tahun 2014. e-Proceeding of Management : Vol.2, No.2 Agustus 2015 | Page 1129.

Kishada dan Wahab. 2015. Influence of Customer Satisfaction, Service Quality, and Trust on Customer Loyalty in Malaysian Islamic Banking. International Journal of Business and Social Science Vol. 6, No. 11; November 2015.

Kotler, Philip dan Gary Armstrong. 2008. Prinsip-prinsip Pemasaran. Edisi 12. Jakarta: Erlangga.

Lupiyoadi, Rambat. 2013. Managemen Pemasaran Jasa Edisi 3. Jakarta: Salemba Empat. Marzuki. 2000. Metodologi Riset. Yogyakarta: BPFE-UII.

Maski, Ghozali. 2010. Analisis Keputusan Nasabah Menabung: Pendekatan Komponen dan Model Logistik Studi Pada Bank Syariah di Malang. Journal of Indonesian Applied Economics, Vol. 4, No. 1.

Muhamad. 2014. Manajemen Dana Bank Syariah. Jakarta: Rajawali Pers.

Ningtyas dan Basuki Rachmad. 2011. Pengaruh Kepercayaan, Komitmen, Komunikasi, Penanganan Masalah Dan Kepuasan Nasabah Terhadap Loyalitas Nasabah Bank 
Muamalat di Surabaya. Journal of Business and Banking Volume 1, No. 1, May 2011, pages $51-60$.

Samuel, Hatane. 2012. Customer Relationship Marketing Pengaruhnya Terhadap Kepercayaan dan Loyalitas Perbankan Nasional. Jurnal Manajemen Pemasaran, Vol. 7, No. 1, April 2012 doi: 10.9744/pemasaran.7.5.33-41 ISSN 1907-235X.

Santoso, Singgih dan Tjiptono Fandy. 2001. Riset Pemasaran: Konsep dan Aplikasi SPSS. Jakarta: PT Elex Media Komputindo.

Sari. 2013. Analisis Pengaruh Banking Service Quality (BSQ) terhadap Kepuasan Nasabah Serta Dampaknya Terhadap Loyalitas Nasabah PT. Bank Rakyat Indonesia (PERSERO) Tbk di Kota Semarang. eprints.dinus.ac.id.

Setyono, Langgeng dkk. 2015. The Effect of Islamic Marketing and Corporate Image on Customer Satisfaction and Customer Loyality. Jurnal Administrasi Bisnis (JAB) | Vol. 27 No. 1 Oktober 2015. administrasibisnis.studentjournal.ub.ac.id.

Simamora, B. 2004. Riset Pemasaran. Jakarta: PT. Gramedia Pustaka Utama. Statistik Perbankan Syariah, Juni 2011- Juni 2016.

Subagyo dan Robin. 2012. Pengaruh Perceived Service Quality, Perceived Value, Satisfaction dan Image Terhadap Customer Loyalty (Studi Kasus Garuda Indonesia). Jurnal Manajemen Pemasaran, Vol. 7, No. 1, April 2012 doi: 10.9744/pemasaran.7.5.42-52. ISSN 1907-235X.

Sugiyono. 2010. Metode Penelitian Pendidikan Pendekatan Kuantitatif, Kualitatif, dan R and D. Bandung: Alfabeta.

Sumardiningsih dkk. 2012. Pengaruh Dimensi Banking Service Quality (BSQ) Terhadap Kepuasan Nasabah Bank. Jurnal Economia, Volume 8, Nomor 2, Oktober 2012: 126.

Tanujaya, Andrea. 2014. Pengaruh Customer Perceived Value Terhadap Customer Loyalty Melalui Customer Satisfaction pada 3second Royal Plaza Surabaya. Jurnal Fakultas Bisnis Jurusan Manajemen Universitas Katolik Widya Mandala Surabaya.

UU No 21 Tahun 2008

www.bankmuamalat.co.id

www.infobanknews.com

www.topbrand.com 